\title{
Cutaneous lontophoresis of Vasoactive Medications in Patients with Scleroderma- Associated Pulmonary Arterial Hypertension
}

\section{Sami Al Ampnti (D Alampns@ccf.org)}

Cleveland Clinic Foundation: Cleveland Clinic https://orcid.org/0000-0002-7648-7738

\section{Allaa Almoushref}

University of Connecticut Health Center: UConn Health

\section{Tawfeq Naal}

Wake Forest Baptist Medical Center

\section{Celia Melillo}

Cleveland Clinic Lerner Research Institute

\section{Kulwant S. Aulak}

Cleveland Clinic Lerner Research Institute

\section{Mostafa K. Ahmed}

Assiut University Faculty of Medicine

\section{Soumya Chatterjee}

Cleveland Clinic Main Campus Hospital: Cleveland Clinic

\section{Kristin Highland}

Cleveland Clinic Main Campus Hospital: Cleveland Clinic

\section{Raed A. Dweik}

Cleveland Clinic Main Campus Hospital: Cleveland Clinic

\section{Adriano Tonelli}

Cleveland Clinic Main Campus Hospital: Cleveland Clinic

\section{Research}

Keywords: systemic sclerosis, pulmonary hypertension, pulmonary arterial hypertension, microvascular dysfunction, cutaneous iontophoresis, laser Doppler flowmetry

Posted Date: January 15th, 2021

DOl: https://doi.org/10.21203/rs.3.rs-144093/v1

License: (c) (1) This work is licensed under a Creative Commons Attribution 4.0 International License. Read Full License 


\section{Abstract}

\section{Background:}

It remains unknown whether the cutaneous microvascular responses are different between patients with scleroderma-associated pulmonary arterial hypertension (SSc-PAH) and SSc without pulmonary hypertension $(\mathrm{PH})$.

\section{Methods:}

We included 59 patients with SSc between March 2013 and September 2019. We divided patients into 4 groups: a) no $\mathrm{PH}$ by right heart catheterization $(\mathrm{RHC})(\mathrm{n}=8), \mathrm{b})$ no $\mathrm{PH}$ by noninvasive screening tests $(n=16), c)$ treatment naïve PAH $(n=16)$ and d) PAH under treatment $(n=19)$. Microvascular studies using laser Doppler flowmetry (LDF) were done immediately after RHC or at the time of an outpatient clinic visit (group b).

\section{Results:}

The median (IQR) age was 59 (54-68) years, and 90\% were females. The responses to thermal and post occlusive reactive hyperemia, acetylcholine, and sodium nitroprusside iontophoresis were similar among groups. The microvascular response to treprostinil was more pronounced in SSc patients without PH by screening tests (\% change: 340 (214-781)) compared with SSc-PAH (naïve + treatment) (Perfusion Units (PU) \% change: 153 (94-255) \% [p=0.01]). The response to A-350619 (a sGC activator) was significantly higher in patients with SSc without PH by screening tests (PU \% change: $168(46-1,296))$ than those with SSc-PAH (PU \% change: 22 (15-57) \% [p=0.006]). The \% change in PU with A350619 was directly associated with cardiac index and stroke volume index ( $\mathrm{R}: 0.36, p=0.03$ and $0.39, p=0.02$, respectively).

\section{Conclusions:}

Patients with SSc-PAH have a lower cutaneous microvascular response to a prostacyclin analog treprostinil and the SGC activator A-350619 when compared with patients with SSc and no evidence of $\mathrm{PH}$ on screening tests.

\section{Introduction}

Systemic sclerosis (SSc) is a complex immune-mediated connective tissue disease characterized by fibrosis and thickening of the skin as well as vascular abnormalities such as pulmonary hypertension $(\mathrm{PH})$ including pulmonary arterial hypertension (PAH), Raynaud phenomenon with or without digital ulcers, telangiectasia and scleroderma renal crisis $(1,2)$. PAH is a condition characterized by progressive remodeling of the pulmonary arteries that eventually leads to right heart failure and death (3). $\mathrm{PAH}$ is a leading cause of mortality in SSc, with a death rate of around $50 \%$ at 3 years $(4,5)$. In the last decades, we experienced important advances in the treatment of SSc associated PAH (SSc-PAH); however, despite 
the availability of effective treatments, mortality remains high and survival curves are worse than in idiopathic PAH (6).

The most recent proceedings from the World Symposium on Pulmonary Hypertension (WSPH) recommend risk assessment as a tool in informing treatment decisions (7). In general, patients with low or intermediate-risk are started on upfront oral combination therapy; while patients at high risk should receive a combination regimen that includes parenteral prostacyclin analogs (7). This treatment approach considers the severity of PAH, but it does not incorporate biological mechanistic information, which is necessary for a refined patient-oriented treatment approach that has the goal of providing the best available care for each individual. As seen in other conditions, such as cancer, there is a growing interest in precision medicine, where treatment selection is based on mechanistic abnormalities. This precision medicine approach in treating certain cancer patients is beneficial in improving outcomes, reducing unnecessary treatments, and their side effects (8).

Currently, there are no established ways to test certain mechanisms of disease in a patient with PAH. We have previously shown that the cutaneous microvascular response to treprostinil iontophoresis is reduced in patients with idiopathic PAH compared to controls (9) supporting that abnormalities in the pulmonary vasomotor biology may be associated with alterations in the cutaneous microvascular vasodilatory response (10). Several other studies have shown evidence of extrapulmonary vascular involvement in PAH (11-14). In patients with SSc (2), abnormal nailfold capillaroscopy findings were more prevalent and severe in patients with SSc-PAH compared with SSc without PAH, furthermore abnormal nailfold capillary changes and avascular areas scores correlated with mean pulmonary artery pressures $(15,16)$.

In the present study, we investigated whether the cutaneous microvascular response to local hyperthermia, temporal vascular occlusion, and several vasoactive drugs using iontophoresis is different in patients with SSc with and without PAH. We hypothesized that patients with SSc-PAH have a more pronounced cutaneous microvascular dysfunction than SSc patients without $\mathrm{PH}$ and that certain microvascular responses may provide an insight into the mechanisms of PAH in patients with SSc.

\section{Methods}

\section{a) Subjects selection and Study Design:}

The study was approved by the institutional review board of the Cleveland Clinic (IRB \# 11-441). All subjects provided written informed consent. We conducted this cross-sectional study between March 2013 and September 2019. We included patients who met the 2013 criteria for SSc by the American College of Rheumatology (ACR) and European League Against Rheumatism (EULAR)(17) and underwent right heart catheterization $(\mathrm{RHC})$ at our institution and were found to have PAH based on the definition of the $6^{\text {th }} \mathrm{WSPH}(18)$ (i.e. mean pulmonary artery pressure (PAP) of $>20 \mathrm{mmHg}$, pulmonary artery wedge pressure $(P A W P) \leq 15 \mathrm{mmHg}$, and pulmonary vascular resistance (PVR) $\geq 3$ Wood Units). 
We also included patients with SSc without $\mathrm{PH}$ that were identified as having $\mathrm{mPAP} \leq 20 \mathrm{mmHg}$ during RHC. RHC in these individuals was done for clinical suspicion of $\mathrm{PH}$, in the context of RVSP $>40 \mathrm{mmHg}$, unexplained dyspnea, or decline in their diffusion capacity of carbon monoxide (DLCO). Furthermore, we recruited SSc patients from the scleroderma clinic (S.C and K.H) who had no evidence of PH on noninvasive screening tests. A low probability of $\mathrm{PH}$ on echo was based on a comprehensive evaluation that included peak tricuspid regurgitation velocity $\leq 2.8 \mathrm{~m} / \mathrm{s}$, normal right ventricular (RV) size and function, normal right atrial (RA) size, no evidence of mid-systolic notching, normal RV outflow Doppler acceleration time, and normal size and collapsibility of the IVC $(19,20)$. We excluded patients with significant ILD ( $\geq 20 \%$ fibrosis on high resolution computed tomography of the chest or forced vital capacity (FVC) $<70 \%(21)$. Furthermore, we excluded $3 \mathrm{SSc}$ patients with mPAP between $(21-24 \mathrm{mmHg})$ with PVR $<3$ Wood units, and 5 SSc patients with post-capillary PH (PAWP $>15 \mathrm{mmHg}$ ).

\section{b) Right heart catheterization:}

The RHC was done in the outpatient setting under local anesthesia (2\% lidocaine). We kept patients on their usual amount of oxygen supplementation or started oxygen in those with pulse oxygenation saturation $\left(\mathrm{SpO}_{2}\right)<90 \%$. Patients had nothing by mouth (NPO) for at least 4 hours and refrained from smoking and caffeinated beverages for at least 12 hours. Hemodynamic determinations were obtained at end-expiration using waveform tracings. Pressure transducers were zeroed at the $4^{\text {th }}$ intercostal level of the mid-axillary line.

\section{c) Microvascular studies:}

Cutaneous microvascular studies were done immediately after the RHC, in a sitting position, and after at least 15 minutes of relaxation while in a quiet room with a stable temperature $\left(72^{\circ} \mathrm{F}\right)$. Microvascular investigations were done in the following sequence: iontophoresis of vasoactive agents (Treprostinil, a soluble guanylate cyclase activator (A350619), acetylcholine and sodium nitroprusside), post-occlusive, and local thermal stimulation. Analysis of the microvascular studies was done using the PeriSoft software (Perimed, Stockholm, Sweden).

The PUs were measured with laser Doppler flowmetry (LDF) as previously described $(2,9,10)$, using the PeriFlux System 5000 and PeriSoft software version 2.5.5 (Perimed, Stockholm, Sweden). For every experiment, we placed the electrodes on different places of the left forearm, after we identified a suitable skin area in the ventromedial forearm, away from visible veins, skin cuts, tattoos or sclera-dermatous changes. The skin was prepped using $70 \%$ isopropyl alcohol. The laser probe was calibrated following the manufacturer's instructions. A drug delivery electrode (PF 383) was embedded with $(0.25-0.30 \mathrm{~mL})$ of the vasoactive agent of choice and then a specific protocol was followed for each medication.

Treprostinil (United Therapeutics Corporation, Durham, North Carolina, USA) $1 \mathrm{mg} / \mathrm{ml}$ was delivered using negative polarity and a current of $20 \mathrm{~mA}$ for 30 minutes. A350619 hydrochloride (Santa Cruz, Dallas, Texas, USA) 7.5mM solution was delivered using positive polarity and a current of $100 \mathrm{~mA}$ for 20 minutes followed by 10 minutes of observation. Acetylcholine (Sigma-Aldrich, St. Louis, Missouri, USA) 1\% 
solution was delivered using positive polarity at a current of $40 \mathrm{~mA}$ for 5 minutes. Sodium nitroprusside (Marathon Pharmaceuticals, Northbrook, Illinois, USA) 1\% solution was delivered using negative polarity at a current of $40 \mathrm{~mA}$ for 5 minutes. Care was taken to ensure a good skin-probe connection and stability of the patient arm to avoid artifacts. We averaged 30-second recording of a steady, artifact-free perfusion unit strip and recorded skin temperature at baseline and peak perfusion. In addition, we documented skin resistance and circuit voltage 1 minute after starting the iontophoresis of each medication. The mechanism of action of the different vasoactive agents delivered by iontophoresis is illustrated in figure 1.

Post occlusive reactive hyperemia was done on the left arm using an integrated laser probe (PF413), a thermostatic probe holder (PF450), and a pressure unit (PF5050). After observing a steady resting perfusion determination for one minute, we inflated the arm cuff to $180 \mathrm{mmHg}$, occluding the vascular flow for 3 minutes. In cases in which the systolic blood pressure was higher, the cuff pressure was raised 10-20 mmHg above systolic blood pressure. The PUs were recorded for 1 minute at baseline flow, 3 minutes during occlusion, and one minute after cuff deflation. We measured resting flow (RF), biological zero (BZ), peak flow (PF), percent change between BZ and PF and between RF and PF and time to maximum perfusion $T M$, time to half hyperemia ( $T H 1)$, time to the half recovery ( $T H 2)$, area under occlusion (AO), area under hyperemia $(\mathrm{AH})$, and the ratio $(\mathrm{AO} / \mathrm{AH}) .(22)$

Thermal hyperemia was performed using an integrated laser probe (PF413), a thermostatic probe holder (PF450). After 2 minutes of a steady consistent baseline, the temperature of the skin was increased to $43.9^{\circ} \mathrm{C}$ within one minute and changes in PUs were recorded over 20 minutes (23).

\section{d) Statistical analysis:}

Continuous data are presented as median (interquartile range (IQR)). Categorical data are summarized as discrete values and percentages $(\mathrm{n}(\%)$ ). Results of the iontophoresis tests are expressed as peak PUs, percentage of variation from baseline, and percentage of maximum thermal hyperemia. Results of post occlusive and thermal hyperemia are expressed as peak PUs and percentage of variation from baseline. Continuous and categorical variables were compared between the study groups using Kruskal-Wallis and Fischer exact test as appropriate. Relationships between variables were assessed using the Spearman correlation coefficient. Receiver operating curves we created using the presence of PAH as a classification variable and reporting area under the curve (AUC) with 95\% confidence interval. Pairwise comparison of the different AUC was provided (24). All $p$ values are two-tailed and a value of $<0.05$ was considered significant. The statistical analyses were performed using the statistical package IBM SPSS, version 20 (IBM; Armonk, New York) and MedCalc, version 14.12.0 (Ostend, Belgium).

\section{Results}

\section{a) Patient characteristics:}


We enrolled 59 unique patients with SSc with a median (IQR) age of 59 (54-68) years, of whom 53 (90\%) were females. Limited cutaneous scleroderma was seen in 43 (73\%). We allocated patients to one of four groups, a) SSc without PH on RHC ( $n=8)$, b) SSc with no evidence of PH on screening tests $(n=16), c)$ treatment naïve SSc-PAH ( $n=16)$ and d) SSc-PAH on PAH therapies $(n=19)$ (Table 1). Echocardiographic evidence of moderate to severe RV systolic dysfunction was noted in about a third of patients with PAH.PAH therapies included single, dual, and triple agents in $5(26 \%), 6(32 \%)$, and $8(42 \%)$ of the patients, respectively. Phosphodiesterase-5 inhibitors (PDE5-i) were given to 17 patients (90\%), endothelin receptor antagonists (ERA) to $12(63 \%)$ and prostacyclin analogues to $11(58 \%)$ patients, of whom 6 (32\%) were on parenteral treatment. We noted similar use of CCB and the presence of systemic diseases among groups (Table 1).

\section{b) Thermal hyperemia and post occlusive reactive hyperemia:}

Thermal hyperemia either absolute peak PU or percentage change was similar among groups (Table 2). All the PORH determinations were similar among groups (Table 2).

\section{c) lontophoresis of vasoactive medications:}

The response to Ach and SNP was not significantly different among groups (Table 3). The response to treprostinil was higher in SSc patients without PH on screening tests (peak PU: 30 (23-54), \% change: 340 (214-781), \% of max vasodilation: 16 (10-21)) compared with SSc-PAH (both treatment naïve or on therapy) (peak PU: 16 (11-23) [p=0.003], \% change: 153 (94-255) [p=0.01], \% of max vasodilation: 7 (5-10) $[p=0.008]$ ) (Figure 2, left panels). The AUC of peak PU, \% change and $\%$ of maximum vasodilation to discriminate between SSc patients without $\mathrm{PH}$ on screening test and SSc-PAH were 0.76 (0.62-0.87), 0.72 (0.58-0.84) and 0.74 (0.59-0.85), respectively (Figure 3, left panel). Pairwise comparisons among the three AUC were not statistically significant.

The response to A-350619 was significantly higher in patients with SSc without PH by echo (peak PU: 20 (12-74), \% change: 168 (46-1,296), \% of max vasodilation: 9 (4-36)) than those with SSc-PAH (peak PU: 8 $(6-10)$ [ $p=0.001]$, \% change: $22(15-57)$ [p=0.006], \% of max vasodilation: $3(2-4)$ [p<0.001]) (Figure 2, right panels). The AUC of peak PU, \% change and \% of maximum vasodilation to discriminate between SSC patients without PH on screening test and SSc-PAH were 0.82 (0.66-0.91), $0.75(0.60-0.87)$ and 0.82 (0.680.92), respectively (Figure 3, right panel). Pairwise comparisons among the three AUC were not statistically significant.

\section{d) Association of cutaneous microvascular studies with clinical determinations.}

Percentage change in PUs and percentage of maximal dilation during the iontophoresis of A350619 showed an inverse relation with NYHA functional class (R: $-0.29, p=0.03$ and $-0.27, p=0.05$, respectively) and estimated right ventricular systolic pressure by echocardiogram ( $R:-0.39, p=0.006, R:-0.41, p=0.005$, respectively) with direct association with lung diffusion of carbon monoxide ( $R: 0.29, p=0.04, R: 0.33$, 
$p=0.02$, respectively). The percentage change in PU with A350619 was directly associated with cardiac index and stroke volume index ( $R: 0.36, p=0.03$ and $0.39, p=0.02$, respectively).

Age, gender, race, body mass index, history of skin ulcers or renal crises, presence of ILD, $\mathrm{SpO}_{2}$, and hemoglobin concentration were not significantly associated with cutaneous microvascular determinations.

\section{Discussion}

The study of the cutaneous microvasculature may provide insights into the pathobiology of PAH $(9,25)$ by the ex-vivo evaluation of pathways involved in the disease process for which we have therapies. Recent investigations showed that patients with SSc-PAH, compared with SSc without PAH, have more pronounced systematic microvascular involvement, such as a higher prevalence of severe Raynaud phenomenon (26), and reduced nailfold capillary density (27). In the present study, we tested the response of the cutaneous microvasculature to a variety of stimuli in patients with SSc, intending to determine whether subjects with SSc-PAH (treatment naïve or under PAH-specific treatment) have different responses than SSc patients without $\mathrm{PH}$ (on $\mathrm{RHC}$ or noninvasive screening tests). We found that the microvascular response to thermal hyperemia, PORH, Ach, and SNP iontophoresis were not significantly different between the groups. Interestingly, the response to treprostinil iontophoresis was more than double in patients with SSc and no evidence of $\mathrm{PH}$ on noninvasive screening, when compared to SSc patients with PAH or those who underwent RHC and were found not to have PAH. Furthermore, the response to A-350619 (a SGC activator) was also significantly higher in SSc patients without evidence of $\mathrm{PH}$ on noninvasive screening tests and was inversely associated with severity of disease in SSc-PAH.

Prostacyclin is synthesized by the endothelial cytoplasmic prostacyclin synthase. Prostacyclin then interacts with receptors in the vascular smooth muscle cells, increasing cAMP levels and causing vasodilation $(28,29)$. Prostacyclin synthase is decreased in the lungs of patients with PAH $(30)$, who also have reduced urinary excretion of a prostacyclin metabolite (31). Furthermore, IP receptors are downregulated in animal models of $\mathrm{PH}$ (32) and in patients with PAH (33). We previously described an abnormal microvasculature response with the iontophoresis of treprostinil in patients with idiopathic PAH compared with controls (9). We now found that cutaneous treprostinil iontophoresis is also significantly reduced in patients with SSc-PAH compared to SSc patients without evidence of $\mathrm{PH}$ on screening. Interestingly, patients with SSc who underwent RHC for suspicion of $\mathrm{PH}$ but did not have $\mathrm{PH}$ (i.e. mean PAP $<20 \mathrm{mmHg}$ ), also had a reduced response to the iontophoresis of treprostinil. This reduced response may reflect an early degree of pulmonary vascular disease as noted by a higher estimated right ventricular systolic pressure on echocardiography, a higher than normal PVR on RHC, and the fact that one patient had $\mathrm{PH}$ on a $\mathrm{RHC}$ done a year after inclusion.

Nitric oxide is actively involved in the microvascular homeostasis (34). NO exerts its effect by stimulating sGC, which is involved in the conversion of GTP to cGMP. The increase in cGMP is responsible for pulmonary vasodilation (35). The NO pathway is affected in PAH (36), and there are 2 groups of therapies 
in the market that target this pathway, i.e. phosphodiesterase- 5 inhibitors and an sGC stimulator. In our study, we tested the effects on the cutaneous microvasculature of agents that enhance the NO pathway, either by increasing its bioavailability (SNP: NO donor, Ach: increases the endothelial production of NO) or its downstream activity (A350619: SGC activator). We did not find a significant difference in the microvascular response to Ach and SNP; however, there were pronounced differences in microvascular response with the iontophoresis of A350619.

A350619 is an activator of SGC that had been previously shown to increase cutaneous perfusion in rats using anodal iontophoresis $(37,38)$. This SGC activator works in a dose-dependent fashion with maximum efficacy in an NO rich environment (37). The failure of provoking pronounced vasodilation in the presence of A350619 in patients with SSc-PAH could be linked to a diminished NO production or rapid destruction (e.g. oxidative stress) before it reaches the SGC (39). Presumably, the iontophoresis of A350619 would cause less vasodilation in a NO scarce environment. This might explain why we did not see a difference in microvascular response in SSc patients with or without PAH when delivering Ach or NPS by iontophoresis.

We did not find a difference among groups in the microvascular response to thermal hyperemia or PORH. Thermal hyperemia causes vasodilation through complex mechanisms, including the activation of neurosensory reflexes during the early peak phase and NO pathways (eNOS activation)(23) during the late plateau phase (40). Thermal hyperemia causes maximum microvascular dilation and can be used as a comparator for other microvascular responses (41-43), thereby reducing spatial differences in absolute baseline and peak PUs during LDF measurement. The mechanisms involved in the post occlusive reactive hyperemia are not well-identified but include the release of ischemic induced metabolites like adenosine, $\mathrm{K}^{+}$, myogenic, and axonal sensory reflexes (44) (45). A recent study showed that the peak flow following pressure release in patients with SSc is decreased compared to matched healthy controls (46) but not between SSc and SSc-PAH patients as shown by our study.

These results represent a step towards improving PAH treatment selection for patients with SSc-PAH, by testing the most prominent vasodilatory signaling pathways through cutaneous iontophoresis. Further studies extending our preliminary findings are necessary to access whether an iontophoresis guided method is better than the current risk-based approach.

Our study has limitations including a) relatively small sample size for each group of SSc patients, especially for those that underwent $\mathrm{RHC}$ and had no $\mathrm{PH}, \mathrm{b}$ ) possible degree of overlap in the $\mathrm{PH}$ group, e.g. some patients may have a combination of $\mathrm{PAH}$ ( $\mathrm{PH}$ group 1) with $\mathrm{PH}$ due to lung diseases and/or hypoxia (PH group 3) and $\mathrm{c}$ ) it is unknown if some of the patients with no $\mathrm{PH}$ on $\mathrm{RHC}$ could have exercise $\mathrm{PH}$. In cases of overlap, the treating and a second physician (ART) agreed on the predominant driver of the PH. Despite being a single-center cross-sectional study, this is the first study that comprehensively tested the cutaneous microvascular response in patients with scleroderma with and without PAH.

\section{Conclusions}


Patients with SSc-PAH have a lower cutaneous microvascular response to the prostacyclin analog treprostinil and the SGC activator A-350619 when compared with SSc patients without evidence of PH on echocardiogram. Further studies testing the value of using these mechanistic data in the treatment of SSc-PAH are certainly needed.

\section{Abbreviations}

Ach: acetylcholine

ANA: antinuclear antibodies

ARBs: angiotensin receptor blockers

CCBs: calcium channel blocker

Cl: cardiac index

CO: cardiac output

DLCO: diffusion capacity of carbon monoxide

DM: diabetes mellitus

eNOS: endothelial nitric oxide synthase

HTN: systemic hypertension

ILD: interstitial lung disease

LDF: laser Doppler flowmetry

NO: nitric oxide

NT-pro BNP: N-terminal-pro brain natriuretic peptide

NVC: nailfold capillaroscopy

PAD: peripheral artery disease

PAH: pulmonary arterial hypertension

PAP: pulmonary artery pressure

PCWP: pulmonary capillary wedge pressure

PGI2: prostacyclin 
$\mathrm{PH}:$ pulmonary hypertension

PORH: post occlusive reactive hyperemia

PVR: pulmonary vascular resistance

PU: perfusion unit

RHC: right heart catheterization

RVSP: right ventricular systolic pressure

sGC: soluble guanylate cyclase

SNP: sodium nitroprusside

SSc: systemic sclerosis

SSc-PAH: systemic sclerosis-associated pulmonary arterial hypertension

TH: thermal hyperemia

\section{Declarations}

\section{a) Ethics approval and consent to participate:}

The study was approved by the institutional review board of the Cleveland Clinic (IRB \# 11-441). All subjects provided written informed consent

\section{b) Consent for publication:}

Not applicable

\section{c) Availability of data and material:}

Available upon request

\section{d) Notation of prior abstract publication/presentation:}

Some results of this study have been reported in the form of a poster at the American Thoracic Society International Conference in May 2019.

\section{e) Funding:}

A.R.T is supported by NIH grand \# R01HL130307. M.K.A was supported by the Egyptian Ministry of Higher Education and Scientific Research Scholarship program grant. 


\section{f) Competing interest:}

Sami Al Ampnti MD: The author has no significant conflicts of interest with any companies or organizations whose products or services may be discussed in this article.

Allaa Almoushref MD: The author has no significant conflicts of interest with any companies or organizations whose products or services may be discussed in this article.

Tawfeq Naal MD: The author has no significant conflicts of interest with any companies or organizations whose products or services may be discussed in this article.

Celia Melillo BS: The author has no significant conflicts of interest with any companies or organizations whose products or services may be discussed in this article.

Mostafa K. Ahmed MD: The author has no significant conflicts of interest with any companies or organizations whose products or services may be discussed in this article.

Chatterjee, Soumya MD: The author has no significant conflicts of interest with any companies or organizations whose products or services may be discussed in this article.

Kristin Highland MD: The author has received speaking fees from United Therapeutics, Actelion, Bayer, Boehringer Ingelheim, Gilead Sciences, and Reata Pharmaceuticals. The author has received grants and contracts from United Therapeutics, Actelion, Bayer, Boehringer Ingelheim, Eiger Biopharmaceuticals, Gilead Sciences, Genetics Pharmaceuticals, and Reata Pharmaceuticals. The author is working as a consultant for United Therapeutics, Boehringer Ingelheim, and Actelion.

Kulwant S. Aulak Ph.D.: The author has no significant conflicts of interest with any companies or organizations whose products or services may be discussed in this article.

Raed A. Dweik MD, MBA: The author has no significant conflicts of interest with any companies or organizations whose products or services may be discussed in this article.

Adriano R. Tonelli MD, MSc: The author has no significant conflicts of interest with any companies or organizations whose products or services may be discussed in this article.

\section{g) Authors' contributions:}

Sami Al Ampnti MD: Participated in the data collection, statistical analysis, interpretation of the results, writing and critical revision of the manuscript for important intellectual content and final approval of the manuscript submitted.

Allaa Almoushref MD: Participated in the design of the study, data collection, interpretation of the results and critical revision of the manuscript for important intellectual content and final approval of the manuscript submitted. 
Tawfeq Naal MD: Participated in the data collection, interpretation of the results and critical revision of the manuscript for important intellectual content and final approval of the manuscript submitted.

Celia Melillo BS: Participated in the data collection, interpretation of the results and critical revision of the manuscript for important intellectual content and final approval of the manuscript submitted.

Mostafa K. Ahmed MD: Participated in the data collection, interpretation of the results and critical revision of the manuscript for important intellectual content and final approval of the manuscript submitted.

Chatterjee, Soumya MD: Participated in the interpretation of the results and critical revision of the manuscript for important intellectual content and final approval of the manuscript submitted.

Kristin Highland MD: Participated in the interpretation of the results and critical revision of the manuscript for important intellectual content and final approval of the manuscript submitted.

Kulwant S. Aulak Ph.D.: Participated in the data collection, interpretation of the results and critical revision of the manuscript for important intellectual content and final approval of the manuscript submitted.

Raed A. Dweik MD, MBA: Participated in the interpretation of the results and critical revision of the manuscript for important intellectual content and final approval of the manuscript submitted.

Adriano R. Tonelli MD, MSc: Participated in the design of the study, data collection, statistical analysis, interpretation of the results, writing and critical revision of the manuscript for important intellectual content and final approval of the manuscript submitted. Dr. Tonelli is the guarantor of the paper, taking responsibility for the integrity of the work as a whole, from inception to published article.

\section{h) Acknowledgments:}

United Therapeutics kindly provided the treprostinil (Remodulin $1 \mathrm{mg} / \mathrm{mL}$ ) used in the study, as part of an investigation-initiated proposal. Besides receiving treprostinil vials, no other monetary support was received from the company for the present study. The authors are indebted to Jennie Newman, L.P.N., for her continued assistance during this project, and to Yvonne Al Abdi for her help in producing figure 1.

\section{References}

1. Denton CP, Khanna D. Systemic sclerosis. Lancet (London, England). 2017;390(10103):1685-99.

2. Saygin D, Highland KB, Tonelli AR. Microvascular involvement in systemic sclerosis and systemic lupus erythematosus. Microcirculation. 2019;26(3):e12440.

3. Tonelli AR, Arelli V, Minai OA, Newman J, Bair N, Heresi GA, et al. Causes and circumstances of death in pulmonary arterial hypertension. Am J Respir Crit Care Med. 2013;188(3):365-9. 
4. Chaisson NF, Hassoun PM. Systemic sclerosis-associated pulmonary arterial hypertension. Chest. 2013;144(4):1346-56.

5. Coghlan JG, Denton CP, Grunig E, Bonderman D, Distler O, Khanna D, et al. Evidence-based detection of pulmonary arterial hypertension in systemic sclerosis: the DETECT study. Ann Rheum Dis. 2014;73(7):1340-9.

6. Almaaitah S, Highland K, Tonelli A. Management of Pulmonary Arterial Hypertension in Patients with Systemic Sclerosis. Integrated Blood Pressure Control. 2020;Volume 13:15-29.

7. Galie N, Channick RN, Frantz RP, Grunig E, Jing ZC, Moiseeva O, et al. Risk stratification and medical therapy of pulmonary arterial hypertension. Eur Respir J. 2019;53(1).

8. Krzyszczyk P, Acevedo A, Davidoff EJ, Timmins LM, Marrero-Berrios I, Patel M, et al. The growing role of precision and personalized medicine for cancer treatment. Technology (Singap World Sci). 2018;6(3-4):79-100.

9. Tonelli AR, Ahmed MK, Alkukhun L, Cikach F, Aulak K, Dweik RA. Treprostinil lontophoresis in Idiopathic Pulmonary Arterial Hypertension. Am J Respir Crit Care Med. 2015;192(8):1014-6.

10. Barnes JW, Tonelli AR, Heresi GA, Newman JE, Mellor NE, Grove DE, et al. Novel methods in pulmonary hypertension phenotyping in the age of precision medicine (2015 Grover Conference series). Pulm Circ. 2016;6(4):439-47.

11. Dababneh L, Cikach F, Alkukhun L, Dweik RA, Tonelli AR. Sublingual microcirculation in pulmonary arterial hypertension. Ann Am Thorac Soc. 2014;11(4):504-12.

12. Tonelli AR, Alkukhun L, Cikach F, Ahmed M, Dweik RA. Are transcutaneous oxygen and carbon dioxide determinations of value in pulmonary arterial hypertension? Microcirculation. 2015;22(4):249-56.

13. Potus F, Malenfant S, Graydon C, Mainguy V, Tremblay E, Breuils-Bonnet S, et al. Impaired angiogenesis and peripheral muscle microcirculation loss contribute to exercise intolerance in pulmonary arterial hypertension. Am J Respir Crit Care Med. 2014;190(3):318-28.

14. Peled N, Bendayan D, Shitrit D, Fox B, Yehoshua L, Kramer MR. Peripheral endothelial dysfunction in patients with pulmonary arterial hypertension. Respir Med. 2008;102(12):1791-6.

15. Caramaschi P, Canestrini S, Martinelli N, Volpe A, Pieropan S, Ferrari M, et al. Scleroderma patients nailfold videocapillaroscopic patterns are associated with disease subset and disease severity. Rheumatology (Oxford). 2007;46(10):1566-9.

16. Riccieri V, Vasile M, lannace N, Stefanantoni K, Sciarra I, Vizza CD, et al. Systemic sclerosis patients with and without pulmonary arterial hypertension: a nailfold capillaroscopy study. Rheumatology (Oxford). 2013;52(8):1525-8.

17. van den Hoogen F, Khanna D, Fransen J, Johnson SR, Baron M, Tyndall A, et al. 2013 classification criteria for systemic sclerosis: an American college of rheumatology/European league against rheumatism collaborative initiative. Ann Rheum Dis. 2013;72(11):1747-55.

18. Condon DF, Nickel NP, Anderson R, Mirza S, de Jesus Perez VA. The 6th World Symposium on Pulmonary Hypertension: what's old is new. F1000Res. 2019;8:F1000 Faculty Rev-888. 
19. Galie N, Humbert M, Vachiery JL, Gibbs S, Lang I, Torbicki A, et al. 2015 ESC/ERS Guidelines for the diagnosis and treatment of pulmonary hypertension: The Joint Task Force for the Diagnosis and Treatment of Pulmonary Hypertension of the European Society of Cardiology (ESC) and the European Respiratory Society (ERS): Endorsed by: Association for European Paediatric and Congenital Cardiology (AEPC), International Society for Heart and Lung Transplantation (ISHLT). Eur Heart J. 2016;37(1):67-119.

20. Ahmed M, Dweik RA, Tonelli AR. What is the best approach to a high systolic pulmonary artery pressure on echocardiography? Cleve Clin J Med. 2016;83(4):256-60.

21. Launay D, Sobanski V, Hachulla E, Humbert M. Pulmonary hypertension in systemic sclerosis: different phenotypes. Eur Respir Rev. 2017;26(145).

22. Morales F, Graaff R, Smit AJ, Bertuglia S, Petoukhova AL, Steenbergen W, et al. How to assess postocclusive reactive hyperaemia by means of laser Doppler perfusion monitoring: application of a standardised protocol to patients with peripheral arterial obstructive disease. Microvasc Res. 2005;69(1-2):17-23.

23. Minson CT, Berry LT, Joyner MJ. Nitric oxide and neurally mediated regulation of skin blood flow during local heating. J Appl Physiol (1985). 2001;91(4):1619-26.

24. DeLong ER, DeLong DM, Clarke-Pearson DL. Comparing the areas under two or more correlated receiver operating characteristic curves: a nonparametric approach. Biometrics. 1988;44(3):837-45.

25. Barnes JW, Tonelli AR, Heresi GA, Newman JE, Mellor NE, Grove DE, et al. Novel methods in pulmonary hypertension phenotyping in the age of precision medicine (2015 Grover Conference series). Pulmonary circulation. 2016;6(4):439-47.

26. Steen V, Medsger TA, Jr. Predictors of isolated pulmonary hypertension in patients with systemic sclerosis and limited cutaneous involvement. Arthritis Rheum. 2003;48(2):516-22.

27. Hofstee HM, Vonk Noordegraaf A, Voskuyl AE, Dijkmans BA, Postmus PE, Smulders YM, et al. Nailfold capillary density is associated with the presence and severity of pulmonary arterial hypertension in systemic sclerosis. Ann Rheum Dis. 2009;68(2):191-5.

28. Pluchart H, Khouri C, Blaise S, Roustit M, Cracowski JL. Targeting the Prostacyclin Pathway: Beyond Pulmonary Arterial Hypertension. Trends Pharmacol Sci. 2017;38(6):512-23.

29. Mitchell JA, Ahmetaj-Shala B, Kirkby NS, Wright WR, Mackenzie LS, Reed DM, et al. Role of prostacyclin in pulmonary hypertension. Glob Cardiol Sci Pract. 2014;2014(4):382-93.

30. Tuder RM, Cool CD, Geraci MW, Wang J, Abman SH, Wright L, et al. Prostacyclin synthase expression is decreased in lungs from patients with severe pulmonary hypertension. Am J Respir Crit Care Med. 1999;159(6):1925-32.

31. Christman BW, McPherson CD, Newman JH, King GA, Bernard GR, Groves BM, et al. An imbalance between the excretion of thromboxane and prostacyclin metabolites in pulmonary hypertension. $\mathrm{N}$ Engl J Med. 1992;327(2):70-5.

32. Lai YJ, Pullamsetti SS, Dony E, Weissmann N, Butrous G, Banat GA, et al. Role of the prostanoid EP4 receptor in iloprost-mediated vasodilatation in pulmonary hypertension. Am J Respir Crit Care Med. 
2008;178(2):188-96.

33. Falcetti E, Hall SM, Phillips PG, Patel J, Morrell NW, Haworth SG, et al. Smooth muscle proliferation and role of the prostacyclin (IP) receptor in idiopathic pulmonary arterial hypertension. Am J Respir Crit Care Med. 2010;182(9):1161-70.

34. Tonelli AR, Haserodt S, Aytekin M, Dweik RA. Nitric oxide deficiency in pulmonary hypertension: Pathobiology and implications for therapy. Pulmonary circulation. 2013;3(1):20-30.

35. Hirst DG, Robson T. Nitric Oxide Physiology and Pathology. In: McCarthy HO, Coulter JA, editors. Nitric Oxide: Methods and Protocols. Totowa, NJ: Humana Press; 2011. p. 1-13.

36. Klinger JR, Abman SH, Gladwin MT. Nitric oxide deficiency and endothelial dysfunction in pulmonary arterial hypertension. Am J Respir Crit Care Med. 2013;188(6):639-46.

37. Miller LN, Nakane M, Hsieh GC, Chang R, Kolasa T, Moreland RB, et al. A-350619: a novel activator of soluble guanylyl cyclase. Life Sci. 2003;72(9):1015-25.

38. Kotzki S, Roustit M, Arnaud C, Boutonnat J, Blaise S, Godin-Ribuot D, et al. Anodal iontophoresis of a soluble guanylate cyclase stimulator induces a sustained increase in skin blood flow in rats. $J$ Pharmacol Exp Ther. 2013;346(3):424-31.

39. Reis GS, Augusto VS, Silveira APC, Jordão AA, Jr., Baddini-Martinez J, Poli Neto O, et al. Oxidativestress biomarkers in patients with pulmonary hypertension. Pulmonary circulation. 2013;3(4):856-61.

40. Johnson JM, Kellogg DL, Jr. Local thermal control of the human cutaneous circulation. J Appl Physiol (1985). 2010;109(4):1229-38.

41. Taylor WF, Johnson JM, O'Leary D, Park MK. Effect of high local temperature on reflex cutaneous vasodilation. J Appl Physiol Respir Environ Exerc Physiol. 1984;57(1):191-6.

42. Johnson JM, O'Leary DS, Taylor WF, Kosiba W. Effect of local warming on forearm reactive hyperaemia. Clin Physiol. 1986;6(4):337-46.

43. Charkoudian N. Skin blood flow in adult human thermoregulation: how it works, when it does not, and why. Mayo Clin Proc. 2003;78(5):603-12.

44. Lorenzo S, Minson CT. Human cutaneous reactive hyperaemia: role of BKCa channels and sensory nerves. The Journal of physiology. 2007;585(Pt 1):295-303.

45. Crecelius AR, Richards JC, Luckasen GJ, Larson DG, Dinenno FA. Reactive hyperemia occurs via activation of inwardly rectifying potassium channels and $\mathrm{Na}+\mathrm{K}+-\mathrm{ATPase}$ in humans. Circ Res. 2013;113(8):1023-32.

46. Della Rossa A, D'Ascanio A, Barsotti S, Stagnaro C, Mosca M. Post-occlusive reactive hyperaemia (POHR) in systemic sclerosis: very early disease (VEDOSS) represents a separate entity compared to established disease. Scand J Rheumatol. 2016;45(5):408-11.

\section{Tables}

\section{Table 1: Baseline characteristics}




\begin{tabular}{|c|c|c|c|c|c|}
\hline & $\begin{array}{l}\text { SSc } \\
\text { without } \\
\text { PAH (with } \\
\text { RHC) }\end{array}$ & $\begin{array}{l}\text { SSc without } \\
\text { PAH } \\
\text { (without } \\
\text { RHC) }\end{array}$ & $\begin{array}{l}\text { SSc-PAH } \\
\text { (treatment } \\
\text { naïve) }\end{array}$ & $\begin{array}{l}\text { SSc-PAH } \\
\text { (on } \\
\text { treatment) }\end{array}$ & $\begin{array}{l}\mathbf{P} \text { (Fischer exact } \\
\text { test and Kruskal- } \\
\text { Wallis test). }\end{array}$ \\
\hline & $\begin{array}{l}\text { Median } \\
(\text { (IQR), n (\%) }\end{array}$ & $\begin{array}{l}\text { Median } \\
\text { (IQR), n (\%) }\end{array}$ & $\begin{array}{l}\text { Median } \\
\text { (IQR), n } \\
(\%)\end{array}$ & $\begin{array}{l}\text { Median } \\
\text { (IQR), n } \\
(\%)\end{array}$ & \\
\hline $\mathrm{n}$ & 8 & 16 & 16 & 19 & \\
\hline Age (years) & $55(46-57)$ & $58(53-66)$ & $66(55-71)$ & $64(58-71)$ & 0.05 \\
\hline Female gender & $8(100)$ & $13(81)$ & $15(94)$ & $17(90)$ & 0.65 \\
\hline White race & $6(75)$ & $14(88)$ & $14(88)$ & $16(84)$ & 0.85 \\
\hline $\begin{array}{l}\text { Body mass index } \\
(\mathrm{kg} / \mathrm{m})\end{array}$ & $26(22-29)$ & $26(20-29)$ & $26(24-33)$ & $28(24-30)$ & 0.62 \\
\hline $\begin{array}{l}\text { WHO functional class } \\
\text { III or IV }\end{array}$ & $1(13)$ & $1(6)$ & $6(38)$ & $13(68)$ & 0.001 \\
\hline \multicolumn{6}{|l|}{ Type of SSc } \\
\hline Limited & $6(75)$ & $9(56.3)$ & $13(81.3)$ & $15(88.2)$ & \multirow[t]{3}{*}{0.41} \\
\hline Diffuse & $1(12.5)$ & $4(25)$ & $2(12.5)$ & $2(11.8)$ & \\
\hline Sine SSc & $1(12.5)$ & $3(18.7)$ & $1(6)$ & $0(0)$ & \\
\hline Hx of skin ulcers & $2(25)$ & $10(63)$ & $11(69)$ & $9(47)$ & 0.20 \\
\hline $\begin{array}{l}\text { Telangiectasia } \\
\text { presence }\end{array}$ & $4(50)$ & $9(56.3)$ & $14(87.5)$ & $14(73.3)$ & 0.14 \\
\hline Hx of SSc renal crises & $1(14)$ & $1(8)$ & $1(7)$ & $1(5)$ & 0.90 \\
\hline Raynaud's syndrome & 7 (87.5) & $16(100)$ & $16(100)$ & $19(100)$ & 0.90 \\
\hline CCB treatment & $3(37.5)$ & $7(43.8)$ & $6(37.5)$ & $8(42.1)$ & 0.98 \\
\hline PDE5 inh treatment & $0(0)$ & $4(25)$ & $2(12.5)$ & $14(73.7)$ & $<0.001$ \\
\hline ARB treatment & $1(12.5)$ & $1(6.3)$ & $1(6.3)$ & $2(10.5)$ & 0.92 \\
\hline SSRI treatment & $1(12.5)$ & $3(18.8)$ & $2(12.5)$ & $3(15.8)$ & 0.96 \\
\hline ILD (presence) * & $3(38)$ & $6(38)$ & $2(13)$ & $13(68)$ & 0.008 \\
\hline DM (presence) & $1(12.5)$ & $4(25)$ & $1(6.3)$ & $2(10.5)$ & 0.44 \\
\hline HTN (presence) & $3(37.5)$ & $6(37.5)$ & $6(37.5)$ & $6(31.6)$ & 0.97 \\
\hline PAD (presence) & $0(0)$ & $0(0)$ & $2(12.5)$ & $1(5.3)$ & 0.37 \\
\hline ANA (positive) & $8(100)$ & 15 (93.8) & 14 (93.3) & $18(100)$ & 0.62 \\
\hline
\end{tabular}




\begin{tabular}{|c|c|c|c|c|c|}
\hline $\begin{array}{l}\text { Anti-centromere Ab } \\
\text { (positive) }\end{array}$ & $2(25)$ & $5(31.3)$ & $10(66.7)$ & $9(50)$ & 0.13 \\
\hline $\begin{array}{l}\text { Anti-DNA } \\
\text { topoisomerase I (anti } \\
\text { Scl-70) Ab (positive) }\end{array}$ & $1(12.5)$ & $5(31.3)$ & $0(0)$ & $0(0)$ & 0.01 \\
\hline $\begin{array}{l}\text { Anti-RNA polymerase } \\
\text { III Ab (positive) }\end{array}$ & $1(12.5)$ & $3(18.8)$ & $0(0)$ & $0(0)$ & 0.1 \\
\hline NT-pro BNP (pg/ml) & $\begin{array}{l}81(68- \\
100)\end{array}$ & $\begin{array}{l}116(76- \\
188)\end{array}$ & $\begin{array}{l}489(249- \\
4,601)\end{array}$ & $\begin{array}{l}793(510- \\
1,950)\end{array}$ & $<0.001$ \\
\hline Hemoglobin (g/dL) & $14(12-14)$ & $13(12-14)$ & $13(12-13)$ & $12(11-14)$ & 0.10 \\
\hline DLCO (\% of predicted) & $53(46-69)$ & 77 (58-92) & $41(33-46)$ & $33(26-45)$ & $<0.001$ \\
\hline $\mathrm{SpO}_{2}(\%)$ & 99 (97-99) & 97 (96-97) & $96(94-98)$ & 96 (95-97) & 0.16 \\
\hline RVSP (mmHg) & $40(30-40)$ & $26(24-31)$ & $64(52-82)$ & $71(58-86)$ & $<0.001$ \\
\hline $\mathrm{RA}(\mathrm{mmHg})$ & $3(1-5)$ & & $8(4-10)$ & $10(7-10)$ & 0.005 \\
\hline PAWP (mmHg) & $5.5(5-8.7)$ & & $\begin{array}{l}11.5(8.2- \\
12.7)\end{array}$ & $12(8-14)$ & 0.009 \\
\hline mPAP (mmHg) & $15(13-18)$ & & 35 (28-49) & $46(38-54)$ & $<0.001$ \\
\hline $\mathrm{Cl}\left(\mathrm{L} / \mathrm{min} / \mathrm{m}^{2}\right)$ & $\begin{array}{l}3.2\left(2.8^{-}\right. \\
3.4)\end{array}$ & & $\begin{array}{l}2.5(2.1- \\
2.8)\end{array}$ & $\begin{array}{l}3.0(2.5- \\
3.5)\end{array}$ & 0.14 \\
\hline $\mathrm{SVI}\left(\mathrm{mL} / \mathrm{m}^{2}\right)$ & $35(30-39)$ & & $34(23-38)$ & $42(28-47)$ & 0.09 \\
\hline PVR (Wood U) & $\begin{array}{l}1.8(1.2- \\
2.1)\end{array}$ & & $\begin{array}{l}4.5(3.7- \\
13.0)\end{array}$ & $\begin{array}{l}6.7(4.8- \\
9.8)\end{array}$ & $<0.001$ \\
\hline
\end{tabular}

Abbreviations: Ab: antibodies, ANA: antinuclear antibodies, ARB: angiotensin receptor blocker, CCB: calcium channel blocker, Cl: cardiac index, DLCO: diffusion capacity of the lung for carbon monoxide, DM: diabetes mellitus, HTN: systemic hypertension, ILD: interstitial lung disease, IQR: interquartile range, mPAP: mean pulmonary arterial pressure, NT-pro BNP: $\mathrm{N}$ terminal-pro hormone brain natriuretic peptide, PAD: peripheral artery disease, PAH: pulmonary arterial hypertension, PAWP: pulmonary arterial wedge pressure, PDE5 inh: phosphodiesterase-5 inhibitors, PVR: pulmonary vascular resistance, RA: right atrium, RHC: right heart catheterization, RNA: ribonucleic acid, RV: right ventricle, RVSP: right ventricular systolic pressure, SSc: scleroderma, SSRI: selective serotonin reuptake inhibitor, SVI: stroke volume index, WHO: World Health Organization. $*<20 \%$ fibrosis on high resolution computed tomography of the chest or forced vital capacity (FVC) $>70 \%$.

Table 2: Cutaneous microvascular testing with thermal hyperemia and PORH 


\begin{tabular}{|c|c|c|c|c|c|}
\hline & $\begin{array}{l}\text { SSc without } \\
\text { PAH (with } \\
\text { RHC) }\end{array}$ & $\begin{array}{l}\text { SSc without } \\
\text { PAH (without } \\
\text { RHC) }\end{array}$ & $\begin{array}{l}\text { SSc-PAH } \\
\text { (treatment } \\
\text { naïve) }\end{array}$ & $\begin{array}{l}\text { SSc-PAH } \\
\text { (on } \\
\text { treatment) }\end{array}$ & $\begin{array}{l}\mathbf{P} \text { (Fischer exact test } \\
\text { and Kruskal-Wallis } \\
\text { test). }\end{array}$ \\
\hline & $\begin{array}{l}\text { Median } \\
\text { (IQR), n (\%) }\end{array}$ & $\begin{array}{l}\text { Median (IQR), } \\
\text { n (\%) }\end{array}$ & $\begin{array}{l}\text { Median } \\
\text { (IQR), n (\%) }\end{array}$ & $\begin{array}{l}\text { Median } \\
\text { (IQR), n } \\
(\%)\end{array}$ & \\
\hline \multicolumn{6}{|c|}{ Thermal hyperemia } \\
\hline $\begin{array}{l}\text { Baseline } \\
\text { electrode } \\
\text { temperature } \\
\left({ }^{\circ} \mathrm{C}\right)\end{array}$ & $\begin{array}{l}25.3(24.6- \\
27.3)\end{array}$ & $\begin{array}{l}26.8(25.8- \\
27.6)\end{array}$ & $\begin{array}{l}26.6(26.1- \\
27.4)\end{array}$ & $\begin{array}{l}27.6 \\
(26.0- \\
28.8)\end{array}$ & 0.22 \\
\hline Baseline PU & $24(14-25)$ & $21(15-25)$ & $19(14-27)$ & $16(12-19)$ & 0.35 \\
\hline $\begin{array}{l}\text { Thermal } \\
\text { hyperemia } \\
\text { (peak PU) }\end{array}$ & $\begin{array}{l}307(272- \\
499)\end{array}$ & $\begin{array}{l}208 \text { (193- } \\
292)\end{array}$ & $\begin{array}{l}248(190- \\
307)\end{array}$ & $\begin{array}{l}321(181- \\
405)\end{array}$ & 0.16 \\
\hline $\begin{array}{l}\text { Thermal } \\
\text { hyperemia (\% } \\
\text { change) }\end{array}$ & $\begin{array}{l}2,049(1,005- \\
3,156)\end{array}$ & $\begin{array}{l}1147(842- \\
1458)\end{array}$ & $\begin{array}{l}1,124(830- \\
1,686)\end{array}$ & $\begin{array}{l}1,982 \\
(1,275- \\
2,267)\end{array}$ & 0.06 \\
\hline \multicolumn{6}{|c|}{ Post occlusive reactive hyperemia } \\
\hline Baseline PU & $20(16-24)$ & $19(15-25)$ & $18(13-21)$ & $19(14-28)$ & 0.92 \\
\hline $\begin{array}{l}\text { Biological zero } \\
\text { PU }\end{array}$ & $6.5(0-11)$ & $7(6-9)$ & $9(7-11)$ & $6(0-9)$ & 0.36 \\
\hline $\begin{array}{l}\text { PORH (peak } \\
\text { PU) }\end{array}$ & $70(37-114)$ & $81(42-95)$ & $\begin{array}{l}72(49- \\
124)\end{array}$ & $\begin{array}{l}84(66- \\
100)\end{array}$ & 0.87 \\
\hline $\begin{array}{l}\text { PORH (\% } \\
\text { change) }\end{array}$ & $\begin{array}{l}344(139- \\
504)\end{array}$ & $\begin{array}{l}286(197- \\
421)\end{array}$ & $\begin{array}{l}369(207- \\
585)\end{array}$ & $\begin{array}{l}316(266- \\
452)\end{array}$ & 0.68 \\
\hline TR (seconds) & $1.1(0.8-2.6)$ & $1.6(0.6-2.5)$ & $\begin{array}{l}1.6(0.7- \\
2.2)\end{array}$ & $\begin{array}{l}1.4(0.8- \\
2.1)\end{array}$ & 0.99 \\
\hline TH1 (seconds) & $3(2-5)$ & $3(2-5)$ & $4(3-6)$ & $3(3-4)$ & 0.31 \\
\hline TM (seconds) & $14(4-16)$ & $16(5-32)$ & $13(8-18)$ & $10(5-13)$ & 0.44 \\
\hline TH2 (seconds) & $31(4-36)$ & $27(9-36)$ & $18(10-24)$ & $21(14-33)$ & 0.63 \\
\hline
\end{tabular}

Abbreviations: IQR: interquartile range, PAH: pulmonary arterial hypertension, PORH: post-occlusive reactive hyperemia, PU: perfusion unit, RHC: right heart catheterization, SSc: scleroderma, $\mathrm{TH}$ : thermal hyperemia, TH1: time to half hyperemia, TH2: time to half recovery, TM: time to maximum perfusion, TR: time to full recovery.

Table 3: Cutaneous microvascular testing with iontophoresis of Treprostinil, Ach, SNP, and A350619. 


\begin{tabular}{|c|c|c|c|c|c|}
\hline & $\begin{array}{l}\text { SSc without } \\
\text { PAH (with } \\
\text { RHC) }\end{array}$ & $\begin{array}{l}\text { SSc without } \\
\text { PAH (without } \\
\text { RHC) }\end{array}$ & $\begin{array}{l}\text { SSc-PAH } \\
\text { (treatment } \\
\text { naïve) }\end{array}$ & $\begin{array}{l}\text { SSc-PAH } \\
\text { (on } \\
\text { treatment) }\end{array}$ & $\begin{array}{l}\mathbf{P} \text { (Fischer exact test } \\
\text { and Kruskal-Wallis } \\
\text { test). }\end{array}$ \\
\hline & $\begin{array}{l}\text { Median } \\
\text { (IQR), n (\%) }\end{array}$ & $\begin{array}{l}\text { Median (IQR), } \\
\text { n (\%) }\end{array}$ & $\begin{array}{l}\text { Median } \\
\text { (IQR), n (\%) }\end{array}$ & $\begin{array}{l}\text { Median } \\
\text { (IQR), n } \\
(\%)\end{array}$ & \\
\hline \multicolumn{6}{|c|}{ Treprostinil iontophoresis } \\
\hline Peak PUs & $12(5-18)$ & $30(23-54)$ & $16(13-22)$ & $16(8-27)$ & 0.008 \\
\hline $\begin{array}{l}\text { Percentage } \\
\text { change in PUs }\end{array}$ & $\begin{array}{l}142(25- \\
275)\end{array}$ & $340(214-781)$ & $\begin{array}{l}150(79- \\
237)\end{array}$ & $\begin{array}{l}159(94- \\
288)\end{array}$ & 0.04 \\
\hline $\begin{array}{l}\text { Percentage of } \\
\text { maximum } \\
\text { dilation }\end{array}$ & $4(2-6)$ & $16(10-21)$ & $7(4-9)$ & $7(5-13)$ & 0.003 \\
\hline $\begin{array}{l}\text { Skin } \\
\text { resistance* }\end{array}$ & $\begin{array}{l}323(230- \\
439)\end{array}$ & $411(341-494)$ & $\begin{array}{l}388(342- \\
487)\end{array}$ & $\begin{array}{l}422(352- \\
544)\end{array}$ & 0.28 \\
\hline Voltage* & $6(5-9)$ & $8(7-10)$ & $8(7-10)$ & $8(7-11)$ & 0.28 \\
\hline $\begin{array}{l}\text { Skin } \\
\text { temperature } \\
\left({ }^{\circ} \mathrm{C}\right)^{\star}\end{array}$ & $28(28-29)$ & $29(29-30)$ & $29(28-30)$ & $29(28-30)$ & 0.12 \\
\hline \multicolumn{6}{|c|}{ Acetylcholine iontophoresis } \\
\hline Peak PUs & $44(21-46)$ & $56(25-69)$ & $27(21-32)$ & $42(19-56)$ & 0.20 \\
\hline $\begin{array}{l}\text { Percentage } \\
\text { change in PUs }\end{array}$ & $\begin{array}{l}572(307- \\
840)\end{array}$ & $\begin{array}{l}615(256- \\
1213)\end{array}$ & $\begin{array}{l}389(281- \\
816)\end{array}$ & $\begin{array}{l}551(274- \\
968)\end{array}$ & 0.79 \\
\hline $\begin{array}{l}\text { Percentage of } \\
\text { maximum } \\
\text { dilation }\end{array}$ & $12(5-15)$ & $17(13-30)$ & $11(8-15)$ & $13(10-17)$ & 0.07 \\
\hline $\begin{array}{l}\text { Skin } \\
\text { resistance* }\end{array}$ & $\begin{array}{l}188(164- \\
218)\end{array}$ & $216(187-250)$ & $\begin{array}{l}197(189- \\
268)\end{array}$ & $\begin{array}{l}219(178- \\
256)\end{array}$ & 0.56 \\
\hline Voltage* & $7(7-9)$ & $9(7-10)$ & $8(7-11)$ & $9(7-10)$ & 0.54 \\
\hline $\begin{array}{l}\text { Skin } \\
\text { temperature } \\
\left({ }^{\circ} \mathrm{C}\right)^{*}\end{array}$ & $27(26-29)$ & $29(28-29)$ & $28(27-29)$ & $28(28-29)$ & 0.22 \\
\hline \multicolumn{6}{|c|}{ Sodium nitroprusside iontophoresis } \\
\hline Peak PUs & $16(12-20)$ & $25(16-42)$ & $15(8-56)$ & $20(15-33)$ & 0.35 \\
\hline $\begin{array}{l}\text { Percentage } \\
\text { change in PUs }\end{array}$ & $\begin{array}{l}228(208- \\
435)\end{array}$ & $302(169-536)$ & $\begin{array}{l}178(66- \\
770)\end{array}$ & $\begin{array}{l}308(192- \\
500)\end{array}$ & 0.88 \\
\hline $\begin{array}{l}\text { Percentage of } \\
\text { maximum } \\
\text { dilation }\end{array}$ & $5(3-7)$ & $12(7-16)$ & 7 (3-31) & $7(4-11)$ & 0.07 \\
\hline
\end{tabular}




\begin{tabular}{|c|c|c|c|c|c|}
\hline $\begin{array}{l}\text { Skin } \\
\text { resistance* }\end{array}$ & $\begin{array}{l}232(185- \\
260)\end{array}$ & $232(192-246)$ & $\begin{array}{l}240(221- \\
266)\end{array}$ & $\begin{array}{l}267(207- \\
310)\end{array}$ & 0.61 \\
\hline Voltage* & $10(8-11)$ & $9(8-10)$ & $10(9-10)$ & $11(8-12)$ & 0.60 \\
\hline $\begin{array}{l}\text { Skin } \\
\text { temperature } \\
\left({ }^{\circ} \mathrm{C}\right)^{*}\end{array}$ & $27(26-29)$ & $28(28-30)$ & $28(27-29)$ & $29(27-29)$ & 0.21 \\
\hline \multicolumn{6}{|c|}{ A-350619 iontophoresis } \\
\hline Peak PUs & $4(3-5)$ & $20(12-74)$ & $8(5-10)$ & $8(7-10)$ & 0.001 \\
\hline $\begin{array}{l}\text { Percentage } \\
\text { change in PUs }\end{array}$ & $25(-12-32)$ & $168(46-1296)$ & $26(15-53)$ & $18(7-60)$ & 0.03 \\
\hline $\begin{array}{l}\text { Percentage of } \\
\text { maximum } \\
\text { dilation }\end{array}$ & $1(0.7-2)$ & $9(4-36)$ & $3(2-5)$ & $3(2-4)$ & $<0.001$ \\
\hline $\begin{array}{l}\text { Skin } \\
\text { resistance* }\end{array}$ & $89(84-101)$ & $111(85-135)$ & $\begin{array}{l}106(95- \\
138)\end{array}$ & $\begin{array}{l}113(96- \\
158)\end{array}$ & 0.21 \\
\hline Voltage* & $9(8-10)$ & $11(8-14)$ & $10(9-13)$ & $11(9-14)$ & 0.41 \\
\hline $\begin{array}{l}\text { Skin } \\
\text { temperature } \\
\left({ }^{\circ} \mathrm{C}\right)^{*}\end{array}$ & $28(27-29)$ & $29(28-29)$ & $28(27-29)$ & $9(28-29)$ & 0.18 \\
\hline
\end{tabular}

Abbreviations: Ach: Acetylcholine, IQR: interquartile range, PAH: pulmonary arterial hypertension, PU: perfusion unit, RHC: right heart catheterization, SNP: sodium nitroprusside, SSc: scleroderma. ${ }^{*}$ Measured at 1 minute of initiating iontophoresis.

\section{Figures}




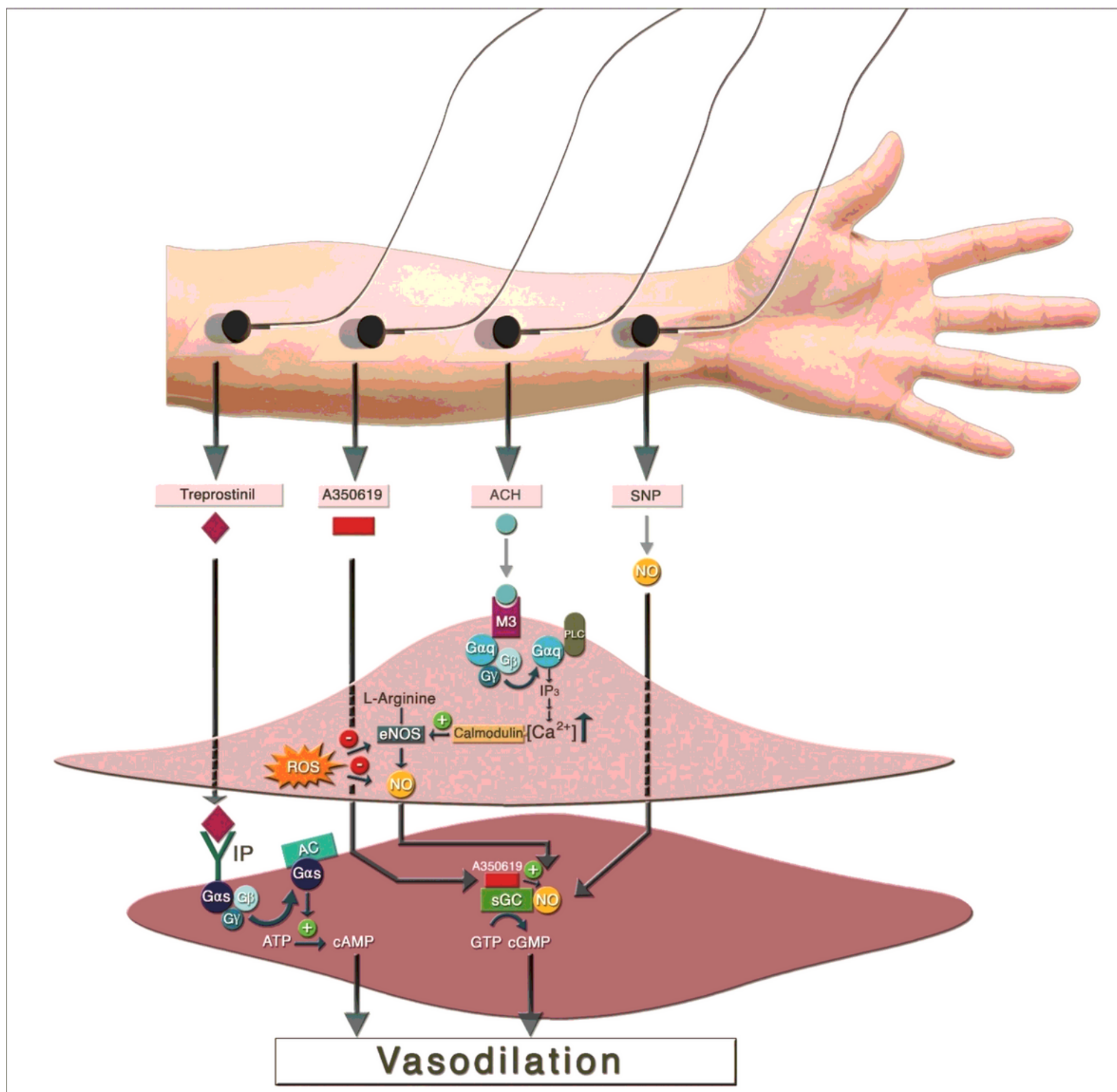

Figure 1

Cutaneous iontophoresis of the vasoactive medications and their effect through PGI2 and NO pathways in SSc-PAH patients. Treprostinil works on several receptors but IP receptors are depicted in the figure. A350619 exerts its effect by activating sGC. Ach works on activating eNOS by increasing intracellular calcium through M3 muscarinic receptors. SNP is a NO donor. Abbreviations: AC: adenylate cyclase, Ach: acetylcholine, ATP: adenosine triphosphate, cAMP: cyclic adenosine monophosphate, cGMP: cyclic guanosine monophosphate, EC: endothelial cell, eNOS: endothelial nitric oxide synthase, GTP: Guanosine- 
5'-triphosphate, IP: prostacyclin receptor, IP3: inositol 1, 4, 5-trisphosphate, NO: nitric oxide, PLC: phospholipase C, ROS: reactive oxygen species, sGC: soluble guanylate cyclase, SMC: smooth muscle cell, SNP: sodium nitroprusside.

Treprostinil lontophoresis

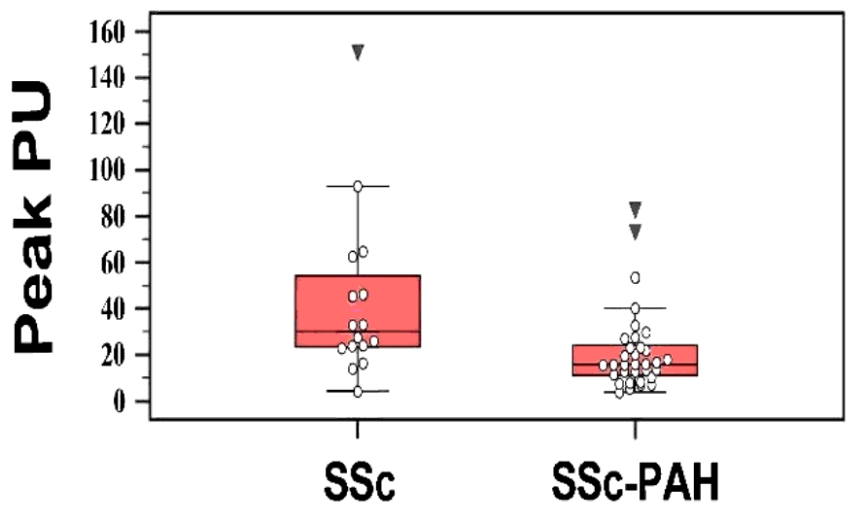

3
0
0
0
0
$\frac{1}{0}$
$\frac{1}{0}$
0

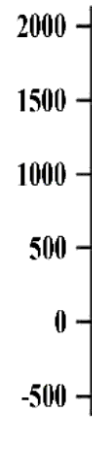

$2000-$
$1500-$
$1000-$
$500-$
$0-500-$
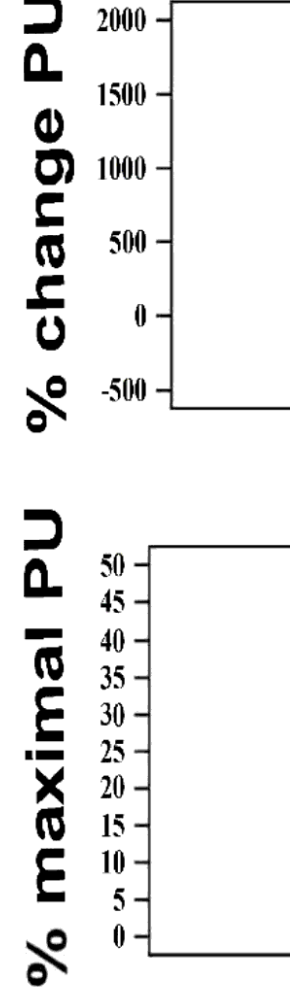

$\frac{2}{2}$

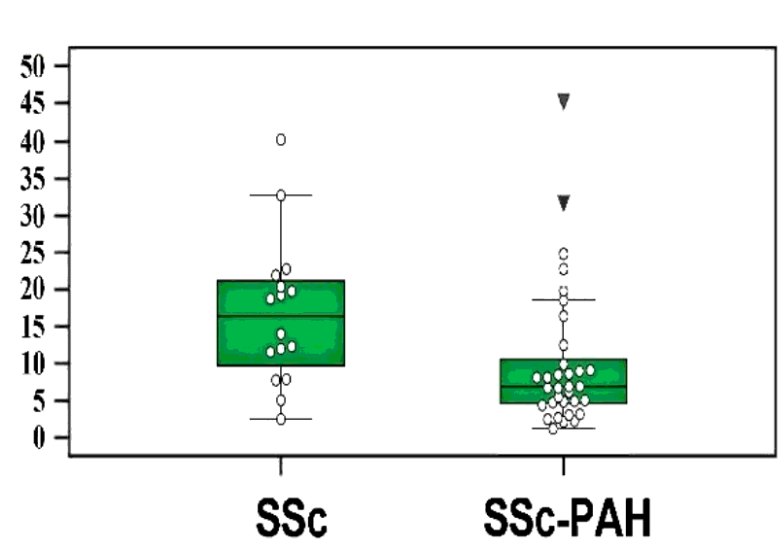

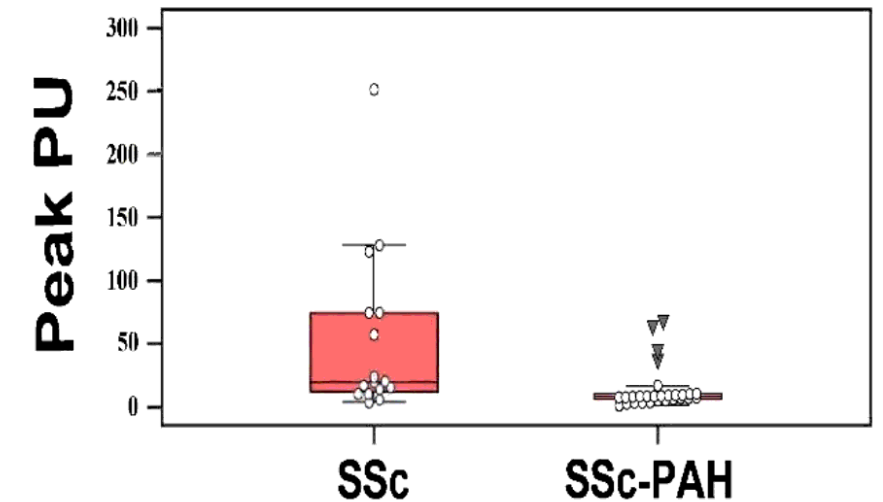

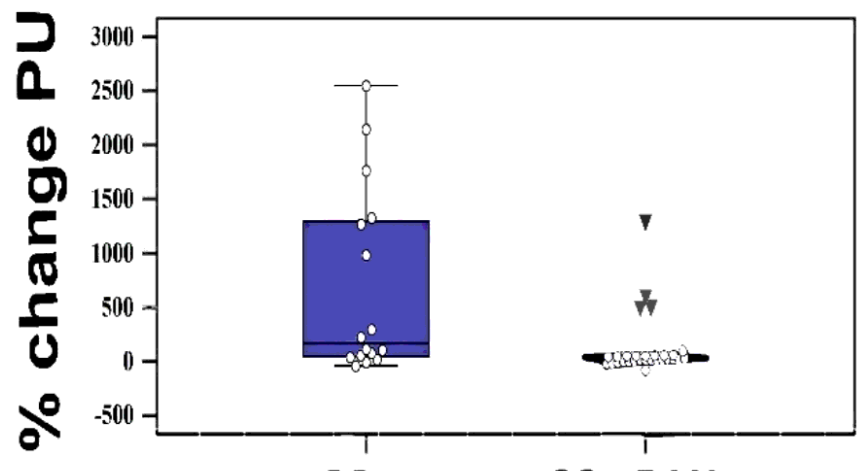

SSc

SSc-PAH

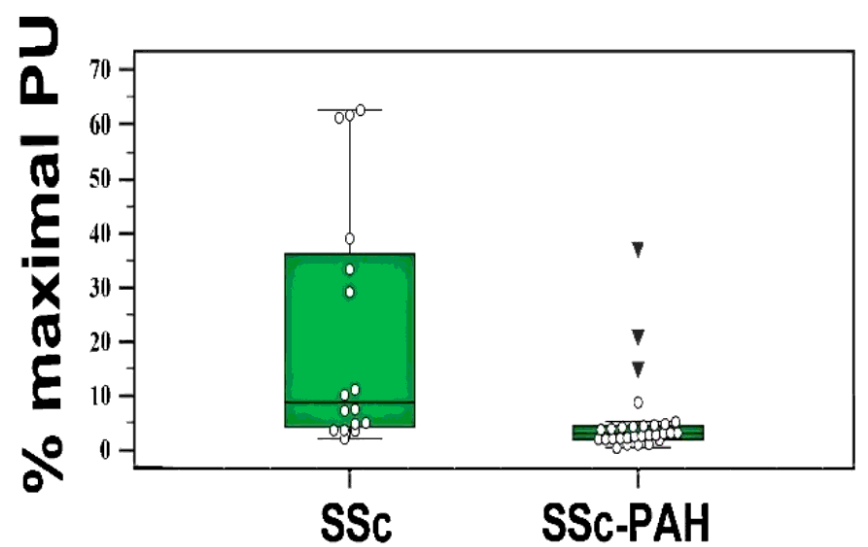

Figure 2

Boxplot of peak PUs, PU percentage change, and PU percentage of maximum thermal hyperemia during the iontophoresis of treprostinil (left panels) and A350619 (right panels) in SSc without PH on screening and SSc-PAH patients. Abbreviations: PU: perfusion unit, SSc: scleroderma, SSc-PAH: sclerodermaassociated pulmonary arterial hypertension. 

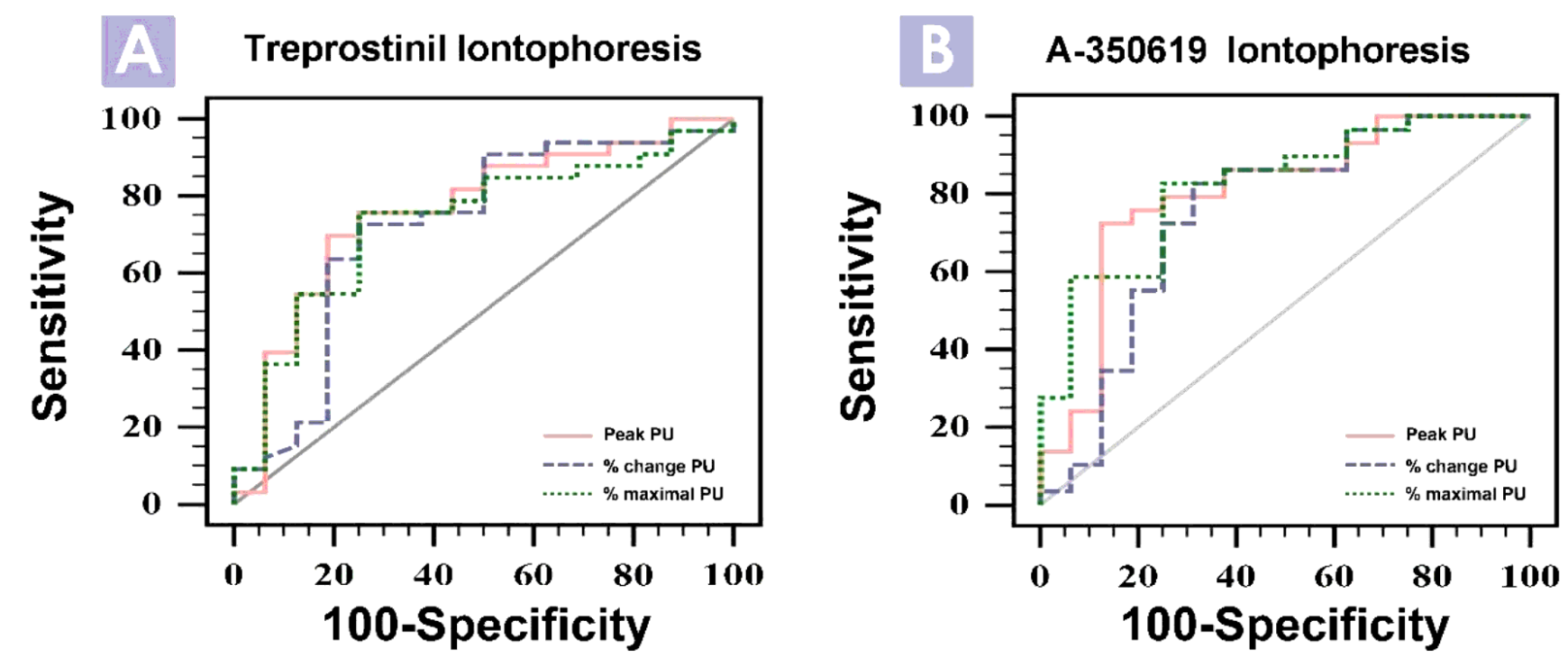

Figure 3

ROC curve of peak PU, PU percentage change, and PU percentage of maximum thermal hyperemia for the iontophoresis results of treprostinil (panel A) and A350619 (panel B). The discriminatory variable was the presence of SSc-PAH. AUC results are provided in the text. Abbreviations: PU: perfusion unit. 